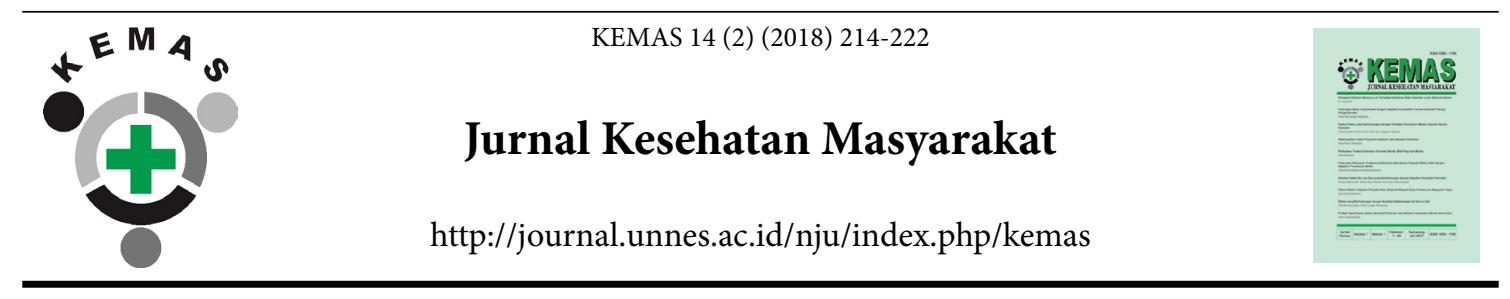

\title{
Supervision of Unsafe Act on Formwork Workers at Project " $X$ ” Bekasi City
}

\author{
Putri Winda Lestari ${ }^{1 \bowtie}$, Novalia Puji Lestari ${ }^{1}$ \\ ${ }^{1}$ Prodi Keselamatan dan Kesehatan Kerja, Universitas Binawan, Indonesia
}

\begin{tabular}{l} 
Article Info \\
\hline Article History: \\
Submitted June 2017 \\
Accepted May 2018 \\
Published November 2018 \\
\hline Keywords: \\
Supervision, Unsafe \\
Behavior, \\
Formwork Workers \\
\hline DOI \\
https://doi.org/10.15294/ \\
kemas.v14i2.9957
\end{tabular}

\begin{abstract}
Former observation results at "X" Project find several unsafe behaviors such as not using personal protective equipment (PPE), smoking and jesting while working. The aim of the study is to determine the association between supervision and unsafe behavior in formwork workers of "X" project Bekasi City. This study used cross sectional design. Independent variable was supervision, whereas dependent variable was unsafe behavior. Study population involved all of the formwork workers (40 people). Data was collected through observation using guided checklist on JSA and interview using valid and reliable questionnaire. Data analysis was conducted by chi-square. The study results showed that 25 respondents $(62.5 \%)$ say that supervision are lacking while 21 respondents $(50.2 \%)$ perform unsafe behavior. P-value of 0.011 means that there is an association between supervision and unsafe behavior, while the prevalence ratio value of 2.550 with $95 \% \mathrm{CI}$ of 1,056-6,155 imply that poor supervision has 2.550 higher risk on the occurrence of unsafe behavior in workers compared to better supervision. In conclusion, there is an association between supervision and unsafe behavior.
\end{abstract}

\section{Introduction}

Construction work is a high risk occupation. Negative consequence may emerge from the building process, such as work accidents (Suarez et al., 2017) organizations, society and countries, Occupational Safety and Health (OSH). This could occurred since construction work mostly take place in an open space, conducted in vast working space, involves building design and material, have unique location condition which requires the workers to adapt from one site to another, and being easy to be accessed by different people in which this would not support the occupational health safety and would lead to higher risk of work accidents. In construction, workers also perform several activities in which every of it has specific risk issue (Grant \& Hinze, 2014).

Work accidents in construction site could reduce productivity and achievement of project goals. Data from literature study shows that there is an estimated 100.000 work accidents per year in Indonesia (Hidayat, Ferial, \& Anggraini, 2016). There are three types of work accidents i.e accident, incident, and near miss. Accident is an unexpected occurrence resulting in loss of worker or property. Incident is an unexpected occurrence which does not result in any loss. Near miss is an occurrence which almost results in misfortune.

In general, work accident is caused by two main factors i.e unsafe act and unsafe conditions. Almost $85 \%$ of the accident is contributed by unsafe act. Based on that fact, 
it could be said that human behavior plays significant role in inflicting certain accident. Factors influencing occupational safety in construction sector include historical factors such as background and individual characteristics, economical factor, psychological factor such as worker behavior and supervision, technical factor such as occupational safety training, and organizational and environmental factors such as policy, economical, psychologic, technical, procedure, organization, and the environmental issues are considered in terms of how these factors are linked with the level of site safety. The historical factor is assessed by the background and characteristics of the individual, such as age and experience. The economic factor is determined by the monetary values which are associated with safety such as, hazard pay. The psychological factor is assessed by the safety behavior of fellow workers on site including supervisors. The technical and procedural factors are assessed by the provision of training and handling of safety equipment on site. The organizational and environmental factors are assessed by the type of policy that the management adopts to site safety. Information regarding these factors were correlated with accidents' records in a sample of 120 operatives. Results of the factor analysis suggest that variables related to the 'organization policy' are the most dominant group of factors influencing safety performance in the United Kingdom Construction Industry.

The Domino Theory stated by Heinrich explains that accidents consist of five associated factors, which are work condition, human error, unsafe action, accident, and injury. Those five factors are arranged like standing dominos. If one card falls, it will hit other cards resulting in falling all together. Heinrich also stated that the key on preventing accident is by eliminating unsafe behavior as the third factor. If the the third card (unsafe behavior) is eliminated, there will be some space between the second and the fourth card. In that case, if the first and second cards are falling (work condition and human error), they will not fall on the fourth and fifth cards (accident and injury). His study also shows that unsafe behavior contributes to $98 \%$ of work accidents.

Construction is a labor intensive industry in which every workers has significant role in embodying the project success. Therefore, worker protection from hazard and accident are considered as important matters in construction company. The Law No. 1 of 1970 stated that one of the purposes of occupational health and safety is protection for workers in the site environment in order to ensure their safety and health so that it may result in increased production and productivity.

In Law No. 36 of 2009 concerning health, article 164 paragraph 1 and 2 concerning occupational health, it is stated that occupational health effort is aimed to protect worker on having healthy lives and free from health disorder and bad impact from work, both for the formal and informal workers. Therefore, several attempts are needed to ensure the occupational health and safety by using working environment control and monitoring (Prayoga, 2014).

The development of " $\mathrm{X}$ " Project in Bekasi City involves several types of works such as mechanical electrical, upper structure (formwork, foundry, iron structure) and lower structure (foundation, excavation). Each type of works has its particular risk. Hazard risks on formwork installation are getting hit by falling scaffolding from its installation, falling from scaffolding, getting punctured by nail, getting hit by hammer, falling while installing ankle, falling from height, getting stuck in formwork, getting hit formwork, or slipping.

Based on the observation performed in the " $\mathrm{X}$ " project, Bekasi city from FebruaryMarch 2016, there were workers who were still undisciplined or behaving unsafely at work, such as working without adherence to existing procedure, not using PPE, wearing PPE inappropriately, or smoking and jesting while working. Theoretically, there are two kind of unsafe behavior i.e error or violation. Unsafe behavior conducted by worker could happened in two conditions. Firstly, the workers do not know that they are performing unsafe behavior, and secondly the worker are aware that they are performing unsafe behavior. In the first case, it could be dealt by providing occupational health and safety training, decent supervision, and well established working system. The second case shows that unsafe behavior are caused by 
several more complex factors such as worker characteristics, motivation, managerial system, and influence by colleagues.

According to the Swiss Cheese theory stated by James Reason, human negligence is caused by four stages i.e unsafe behavior, precondition with potency of causing unsafe action, unsafe supervision, and organizational influence. In this theory, various types of negligence represent holes on a cheese. If all of those four cheeses have hole, then accident could be unavoidable. Observation on the project shows that safety department still acts suboptimally in field supervision due to vast working area and lack of health and safety environment (HSE) officers.

This study aims to determine the association between supervision and unsafe behavior of formwork workers in "X" project, Bekasi City so that future attempts could be arranged to reduce the unsafe behavior of worker in construction sector in general and formwork worker in "X" Project, Bekasi City in particular.

Methods

This research was an analytical observational study with cross sectional design, a study design performed non-experimentally with point time approach model to analyze the dynamical influence between risk factor and effect. It was held in February - April 2016 in "X" Project, Bekasi City. Research population involved all formwork workers numbering 40 people. Due to the relatively small population, all of the population was enrolled as study sample (total sampling). Each subject was only observed once, while risk factor and effect were measured based on the time the observation were performed. Chosen sample were population fulfilling the inclusion criteria i.e formwork workers in " $\mathrm{X}$ " Project, Bekasi City and agreed to be research respondents.

The independent variable was supervision while dependent variable was unsafe behavior. Instrument in this study were questionnaire and checklist sheet. Questionnaire were used to measure the independent variables i.e supervision with Guttman scale in the form of positive statements valued as 1 if true and 0 if false. While for the negative statements, the rule was the opposite. Each examined variable were categorized into two i.e lack of supervision and well supervision for independent variable, while for dependent variable it was unsafe and safe behavior. These categories of variables were based on the mean value, since the characteristic of the data was normal. The questionnaire has been examined for both validity and reliability. The checklist sheet was referred to as Job Safety Analysis (JSA) which was used to determine the dependent variables in form of unsafe behavior of formwork job.

Data collection was performed in interview and observation technique. Data regarding supervision was collected by interview using questionnaire for formwork workers. Data regarding unsafe behavior was collected by observation using JSA-guided checklist sheet. Before being interviewed, respondents were given explanation before consenting to the interviewer and then they filled the informed consent form.

Data were analyzed in uni-variate by looking at the frequency distribution and in bivariate by cross tabulating the dependent and independent variables. Chi square test was used to analyze the statistical test with $\alpha=0.05$ and 95\% confident interval and prevalence ratio was also determined. Data presentation used narration, cross table, and graph.

\section{Results and Discussions}

Results showed that the respondent characteristics were as followed: most of the respondents were 18-40 years old with group of older adult (26-40 years old) consisted of 19 respondents $(47.5 \%)$ and group of younger adult (18-25 years old) was 17 respondents (42.5\%); most of the respondents had Junior and Senior High School level of education accounting for 15 respondents (37.5\%) for each group; and most of the respondents had more than three years of service i.e 23 respondents (57.5\%) (Table 1).

The univariate analysis results showed that 25 respondents felt that supervision in "X" Project were still lacking (62.5\%) and 21 respondents behaved unsafely (50.2\%). Study conducted in construction between 2009 and 2013 reveal that training factor, housekeeping, and supervision are still being implemented poorly in construction site (Mohammadfam et al., 2014). 
Table 1. Respondent Characteristics of Formwork Workers of "X" Projects Bekasi City

\begin{tabular}{llc}
\hline Characteristics & $\mathrm{n}$ & $\%$ \\
\hline Age (Years) & & \\
Younger adult $(18-25)$ & 17 & 42.5 \\
Older adult $(26-40)$ & 19 & 47.5 \\
Full adult $(41-60)$ & 4 & 10.0 \\
Total & 40 & 100.0 \\
Education & & \\
Elementary School & 10 & 24.5 \\
Junior High School & 15 & 37.5 \\
Senior High School & 15 & 37.5 \\
Total & 40 & 100.0 \\
Years of working & & \\
$\leq 3$ years & 17 & 42.5 \\
$>3$ years & 23 & 57.5 \\
\hline Total & 40 & 100.0 \\
\hline
\end{tabular}

Source: Primary Data

This study also shows that supervision activity by HSE are still lacking since one vast construction site along with numerous number of worker are only supervised by several HSE officer. Supervision conducted in the project are mostly performed in the ground level, while the upper level or high level are almost unsupervised. However, risk of having accident also exists for upper level workers. Data for unsafe behavior show that many of the workers do not wear body harness or do not hook the harness. Those facts are in accordance with the reported lack of supervision in upper level work.

Unsafe behavior is every action deviating from the standard operational procedure which could increase the chance of accident. Several unsafe behavior in construction are working without authority which could be possible because of inability to work for the needed field or not used to working process so that those may lead to increased risk of accident; inability to secure or warn colleagues from hazard; working in high pace; lifting or moving objects in inappropriate posture; placing or stacking objects in the wrong location which could jeopardize worker; using inappropriate working equipment; working with damaged equipment; jesting while working; not wearing PPE; wearing PPE inappropriately; relocating safety guard from the work place so that it may cause other workers accidents; smoking and/or setting up fire near flammable objects; leaving sharp things such as nail, wood cut; throwing or unintentionally dropping objects from high place risking others in the lower place; working under influence; having in-ergonomical posture such as climbing rather than using stairs; working with low concentration; working under unfit condition such as overtired or sleepy.

The most frequent unsafe acts during working in this project were not wearing safety gloves $(87,5 \%)$, non-adherence to SOP (75\%), unfastened body harness $(62,5 \%)$, not wearing body harness $(60 \%)$ (Figure 1$)$. The unsafe acts were the main contributor of the work accident in the project site. A research in Thailand showed that no Personal Protective Equipment (PPE) use was the most prevalent unsafe act. Other findings were lifting weight in improper posture and also leaving sharp object in the working site that could harm other workers (Aksorn \& Hadikusumo, 2007)not much work has been done to address the reasons why unsafe acts of workers occur particularly in construction industry. The aim of this paper therefore, is to investigate the major unsafe acts (i.e., at-risk behavior). Unsafe act such as disobedient to the SOP was the main cause of accident in the working site when it was 
combined with the unsafe working situation like bad weather (Chi et al., 2013).

The research result presented that of the 25 unsupervised respondents, 17 respondents acted unsafely and 8 respondents acted safely, while of the 15 supervised respondents, 4 respondents acted unsafely and the others acted safely (Table 2).

Statistical result using chi square test obtained $\mathrm{p}$ value $=0.011(\mathrm{p}<0.05)$ which showed an association between supervision and unsafe act of workers. Prevalence ratio showed a value of 2.550 with $95 \%$ confidence interval (1.056 - 6.155), thus indicating that less supervision contributed to 2.550 times risk of unsafe act compared to proper supervision. This is a convincing result that insufficient supervision was a risk factor for unsafe act during work (Table 2).

The research result proved a significant association between supervision and unsafe acts of formwork workers in Project "X" Bekasi city. Lack of supervision have 2.550 times greater risk for unsafe acts of workers. It was consistent with the theory that supervision was needed to ensure implementation of occupational health and safety (OHS) in a corporation. Supervision with the following regulation was one of the factors affecting individual's act or behavior.

Supervision was one of occupational environment factor and as organizational factor that could initiated unsafe act at work when supervision was inadequate. In every successful safety program implements supervision.

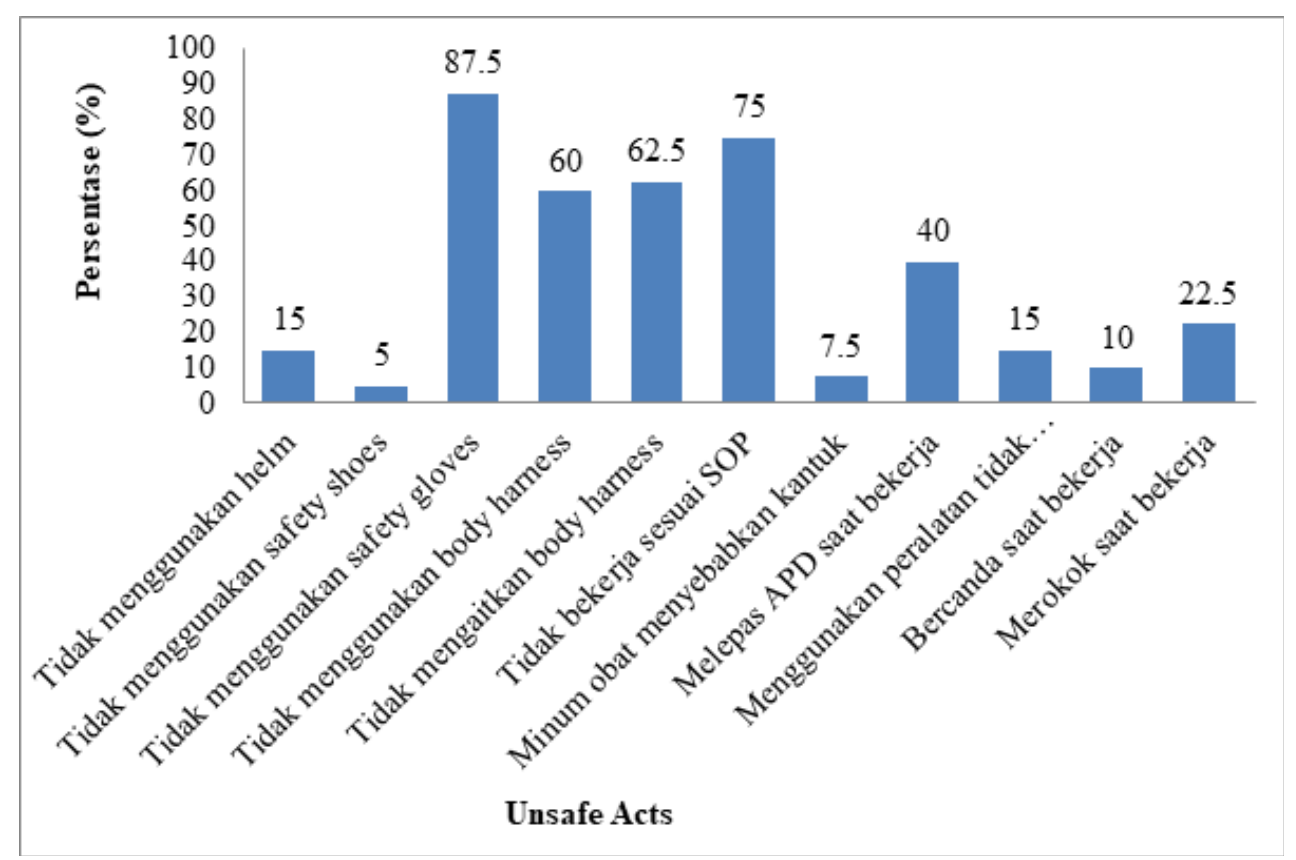

Figure 1. Distribution of Unsafe Act Types of the Formwork Workers Project "X" Bekasi City

Table 2. Association between Supervision and Unsafe Acts on The Formwork Workers Project "X" Bekasi City

\begin{tabular}{|c|c|c|c|c|c|c|c|c|}
\hline \multirow{3}{*}{ Supervision } & \multicolumn{4}{|c|}{ Act } & \multirow{2}{*}{ Total } & \multirow{3}{*}{$\mathrm{p}$ value } & \multirow{3}{*}{$\mathrm{PR}$} & \multirow{3}{*}{$95 \%(\mathrm{CI})$} \\
\hline & \multicolumn{2}{|c|}{ Unsafe } & \multicolumn{2}{|c|}{ Safe } & & & & \\
\hline & $\mathrm{n}$ & $\%$ & $\mathrm{n}$ & $\%$ & $\mathrm{n}$ & & & \\
\hline Less & 17 & 68.00 & 8 & 32.00 & 25 & & & \\
\hline Well & 4 & 26.67 & 11 & 73.33 & 15 & 0.011 & 2.550 & $1.056-0.155$ \\
\hline
\end{tabular}

Source: Primary Data 
Supervisors should properly monitor/control every activity of the workers. If the supervisor could assure the worker, they would act safely and prevent accident to occur.

Good supervision could improve work effectiveness, efficiency and productivity. Supervision could minimize even eliminate deviations from predetermined working plan or working standard. Therefore, the activity would run accordingly to the SOP and working accident could be reduced or eliminated. It would positively impact the workers' performances.

When compared to previous research in other countries, this research was consistent with Fang et al. that reported the direct and indirect impacts of supervision on the safe act of the workers in Hong Kong construction industry. Supervision might improve behavior and safe work climate (Fang, Wu, \& Wu, 2015) management behavior is drawing more and more academic attention because it tends to be the root cause of occupational safety accidents. The current Behavior Based Safety (BBS). Five variables that provided huge impact on safety behavior including supervision, equipment management, OHS norms and cultures, attitude on risk taking, and management behavior.

Zohar in his study in Israel stated that supervision led to improvement of safety behavior and environment in a corporation. Supervision would be more optimal when it consisted of weekly report for monitoring and evaluation (Zohar \& Luria, 2003)and used this to self-monitor progress toward designated improvement goals. Managers higher up in the organizational hierarchy received the same information, coupled with synchronous data concerning the frequency of workers' safety behaviors, and highlighting co-variation of supervisory action and workers' behavior.

In all the companies involved, supervisory safety-oriented interaction increased significantly, resulting in significant changes in workers' safety behavior and safety climate scores. Continued improvement during the post-intervention period suggests the inclusion of workers' safety behavior as inrole supervisory responsibility. Applied and theoretical implications are discussed (Zohar \& Luria, 2003). Beside the weekly report, there could be daily, weekly, and monthly report, and per divisions report as well. A regular and sustainable report could visualize the achievement on safe working and changes in the workers' behavior from time to time which would help the management for evaluation.

Supervision was one of the efforts to reduce unsafe acts, employee selection, and supervision to eliminate unsafe acts. It was noted that no substantial improvements in workplace safety have been achieved after several years of applying this approach even when it was combined with worksite inspections as mandated by the Occupational Safety and Health Act. A new behavioral approach to workplace safety was based on the premises that safety performance can be improved if it is related to specific behaviors on a day by day basis, adequate training to clearly communicate the desired behaviors and relate them to accident and injury experiences is provided, regular and continuous feedback on performance levels achieved is given, individual and unit performance are rewarded when the desired behaviors are observed, and new training elements are periodically rotated into the program. The components of a behavioral safety program based on the new approach were described. The results of field experiments in which behavioral safety programs were used were discussed. The programs when first implemented were successful in promoting safe behaviors; however, in many cases, the effects (new behaviors). Supervision provided possibility for everyone to notice and remind each other when any unsafe act occurred, therefore the unsafe act could be corrected immediately while also minimizing the occurrence of accident. The research by Rowlinson also concluded that supervisor play a key role in ensuring safety management system to run optimally. This suggested that the higher management position would rather put greater attention to supervisors and workers (Rowlinson et al., 2003). 69 foremen from 13 Hong Kong construction companies were invited to participate in a study designed to investigate foremens opinions regarding 27 safety supervisory tasks. These fell into six categories, including handling new workers, training, safety, discipline, coordinating, 
and motivating. Results of the survey and subsequent follow-up interviews showed that over two thirds of foremen claimed that they had the responsibility to perform certain tasks but only half said that they had the authority to perform these tasks. Further interviews and on-site observations of foremen were then conducted in order to validate the findings by way of case study material. It is concluded that foremen play a key role in ensuring that safety management systems operate effectively. It appears, from the results of the study, that this role is not being performed properly and that the key interface between worker and management, the role of the foreman, is not paid sufficient attention by senior management and is an area requiring urgent attention if Hong Kongs poor site safety record is to be improved (Rowlinson et al., 2003). The early step was to build good communication and relation between management and workers. During work, supervisor would meet many workers with diverse backgrounds, situations, and interests. Therefore, supervisor must have social competence, especially in establishing partnership with workers and other stakeholders. The supervisor team was expected to be capable of communicating effectively with all parties, especially the supervised workers. Effective communication was the essential ability to have because it determined the planning, organization, and controlling function.

The whole situation determined individual's behavior. Each person acted differently based on their self perception and environment. Development of their behavior was affected by surrounding environment (Aditya Marianti, Anies, 2015). Implication of this research was to improve unsafe act through supervision as the one of the efforts. With supervision, unsafe act could be detected early for immediate correction. Good supervision was comprehensive, consistent, and provided report or feedback from the lowest to the highest level. This was consistent to the experimental study by Zohar that showed improvement on safety orientation of experimental group followed by positive behavior shift when supervisor provided weekly feedback. The same goes if the senior manager provided feedback for the higher position (Zohar, 2002). Tuming safety priority into an explicit performance goal. Safety-oriented interaction increased significantly in the experimental groups but remained unchanged in the control groups. This change in safety-oriented interaction was accompanied by significant and stable. Supervisor to put greater attention on workers' performances, provide feedback, and also improve communication. These measures was to achieve more effective supervision.

The supervision-related factors were feedback, communication, relation with senior and managerial support. Supervision style also affected workers' behavior (Khosravi et al., 2014). Feedback could measure finished performance, cause of deviations such as unsafe act, and any findings for improvement in the future. Research in China recommended a supervision mechanism in construction sector to be performed in two phase: supervision system by the contractor corporation and supervision system by government (Wu et al., 2012).

In Indonesia, the supervision system should have been performed in at least three level, the first was in subcontractor level. It was because the construction corporation collaborate with several subcontractor. The second was supervision by contractor corporation, and the third was supervision by Government. Supervision by several parties could minimize occurrence of deviations, including the unsafe acts. Commitment from the subcontractor, construction corporation, and Government were essential to achieve safety at work.

Supervision should be regularly performed or as often as possible to inspect dangerous act or activity and to issue immediate improvement. Good supervision should be in a manner of fact finding (finding facts in the field), preventive (preventing deviations), focus on present time, be a tool for efficiency improvement and could not be perceived as a goal, ease to achieve goal, find what was wrong not who was wrong, and guide or direct. Basically, supervision is not just careful watching and reporting, but also serve to correct mistakes so that in the future it could be a reference to arrange better regulation. 
There were three types of supervision: preliminary control, concurrent control, and feedback control. Preliminary control was a managerial effort with a purpose of improving possibility that the work result would be equal or at least approach estimation. In this case, the example was the predetermined implementation of regulation. Preliminary control included control on human resource, tools and materials for work. Concurrent control was supervision in directing workers during performance. In this context, the supervisor provided a direction not only about way of working but also about the attitude in giving direction. Feedback control was supervision focused on the historical results as reference to correct future actions, such as quality control or evaluation of work by workers.

The focused supervision in this project was mostly in a form of concurrent control. Preliminary control was not well performed even though it could minimize deviations in its early phase. Supervision on human resource was consideration in selection, such as certified workers or experienced workers and good record workers for safety concern. Before the project started, supervisors should educate workers on achieving safe work, explain the procedure of every tasks, explain all potential hazards and how to deal with it. Supervision on tools and material should be a priority too. Supervisors had a responsibility to ensure that tools and materials were safe and ready to use.

This research found that un-optimal supervision in the project due to the lack of supervisors, in this case was HSE officers. The large number of workers was not proportional with the number of HSE officers. The compensation of this situation was by facilitating workers to obtain certification for OHS construction, collaborating with foreman of subcontractor to perform control, giving rewards to workers who adhere to SOP, and providing access to report other workers deviations.

Implementation of Occupational Health and Safety became an important aspect as an effort to protect workers in fulfilling their rights for safety in workplace, warranting that the workers are spared from danger during work, and protecting all assets in the workplace such as production sources that was used safely and efficiently (Maywati, 2012). Without adequate supervision, implementation of OHS could not be achieved (Yogisutanti, 2013).

\section{Conclusion}

This research concluded that most of the respondents stated that the supervision in Project " $X$ " Bekasi City was inadequate and most respondents acted unsafely. There was association between supervision and unsafe act on the formworker workers in Project "X" Bekasi City with p value $=0.011$. Prevalence ratio value was 2.550 with $95 \%$ confidence interval value of $1.056-6.155$ which mean inadequate supervision contributed 2.550 times higher risk of unsafe behavior of workers compared to adequate supervision.

It suggested to the corporation running Project "X" Bekasi City that in order to have strong commitment in manifesting OHS, the safety inspectors should be bold, provided reward and punishment, performed comprehensive and consistent control, involved foreman to help in supervision, and performed supervision report regularly (daily, weekly, or monthly, and per division). Beside direct supervision, indirect supervision could also be performed by analyzing related documents such as work implementation report. It suggested for workers to act safely, comply to SOP, commit to actualize safe behavior and environment. Further research was needed to compare effective supervision style in achieving safe behavior on workers.

\section{References}

Aditya, M., \& Anies, H.R.S.A., 2015. Peningkatan Kadar Timbal Darah dan Munculnya Perilaku Antisossial Pengrajin Kuningan. Jurnal Kesehatan Masyarakat, Kemas,11(1), pp.144-154.

Aksorn, T., \& Hadikusumo, B.H.W., 2007. The Unsafe Acts and the Decision-to-Err Factors of Thai Construction Workers. Journal of Construction in Developing Countries, 12(1), pp.1-25.

Chi, S., Han, S., Asce, M., \& Kim, D.Y., 2013. Relationship between Unsafe Working Conditions and Workers' Behavior and Impact of Working Conditions on Injury Severity in U.S. Construction Industry. Journal of Construction Engineering and Management, 139(July), pp.826-838. 
Fang, D., Wu, C., \& Wu, H., 2015. Impact of the Supervisor on Worker Safety Behavior in Construction Projects. Journal of Management in Engineering, 31(6), pp.4015001.

Grant, A., \& Hinze, J., 2014. Construction Worker Fatalities Related to Trusses: An analysis of the OSHA Fatality and Catastrophic Incident Database. Safety Science, 65, pp.54-62.

Hidayat, B., Ferial, R., \& Anggraini, N., 2016. Kecelakaan Kerja Proyek Konstruksi di Indonesia Tahun 2005-2015: Tinjauan Content Analysis dari Artikel. Konferensi Nasional Teknik Sipil 10, (October), pp.316318.

Khosravi, Y., Asilian-Mahabadi, H., Hajizadeh, E., Hassanzadeh-Rangi, N., Bastani, H., \& Behzadan, A.H., 2014. Factors Influencing Unsafe Behaviors and Accidents on Construction Sites: A Review. International Journal of Occupational Safety and Ergonomics, 20(1), pp.111-125.

Maywati, S., 2012. Kajian Faktor Individu Terhadap Kadar Fenol Urin Pekerja Bagian Pengeleman Sandal. Jurnal Kesehatan Masyarakat, 7(24), pp.137-143.

Mohammadfam, I., Soltanzadeh, A., Moghimbeigi, A., \& Akbarzadeh, M., 2014. Factors Affecting Occupational Accidents in the Construction. Johe, 3(2).

Prayoga, H.A., 2014. Intensitas Pencahayaan dan kelainan Refraksi Mata Terhadap Kelelahan
Mata. Jurnal Kesehatan Masyarakat, 9(2), pp.1131-1136.

Rowlinson, S., Mohamed, S., \& Lam, S.W., 2003.

Hong Kong Construction Foremen's Safety Responsibilities: A Case Study of Management Oversight. Engineering, Construction and Architectural Management, 10(1), pp.27-35.

Suarez Sanchez, F.A., Carvajal Pelaez, G.I., \& Catala Alis, J., 2017. Occupational Safety and Health in Construction: A Review of Applications and Trends. Industrial Health, 55(3), pp.210218.

Wu, Yunna., Huang, Yong., Zhang, Shuo., \& Zhang, Y., 2012. Quality Self Control and Co Supervision Mechanism of Construction Technische Informationsbibliothek (TIB). Habitat International, 36(4), pp.471-480.

Yogisutanti, G., Kusnanto, H., Setyawati, L., \& Otsuka, Y., 2013. Kebiasaan Makan Pagi, Lama Tidur dan Kelelahan Kerja (Fatigue) Pada Dosen. Jurnal Kesehatan Masyarakat, 9(1), pp.53-57.

Zohar, D., 2002. Modifying Supervisory Practices to Improve Subunit Safety: A Leadership-based Intervention Model. The Journal of Applied Psychology, 87(1), pp.156-163.

Zohar, D., \& Luria, G., 2003. The Use of Supervisory Practices as Leverage to Improve Safety Behavior: A Cross-level Intervention Model. Journal of Safety Research, 34(5), pp.567-577. 